Avaliação da Saúde e Segurança dos Trabalhadores da Usina de Triagem do Município de Cianorte/PR

Tamyris Tavares da Silva Mestre, UEM, Brasil tamyris_tavares@hotmai.com

Generoso De Angelis Neto Professor Doutor, UEM, Brasil ganeto@uem.br 


\section{Revista Latino-americana de}

Ambiente Construído \& Sustentabilidade

ISSN 2675-7524 / v. 1, n. 2 (2020)

\section{RESUMO}

Nos dias atuais, as usinas de triagem vêm sendo amplamente implantadas no Brasil como um importante elemento para o tratamento dos resíduos sólidos urbanos. Porém, como em qualquer outra atividade laboral, nesses locais os trabalhadores estão expostos a riscos ocupacionais que podem comprometer a sua saúde e segurança. Esta pesquisa tem como base a análise da saúde e segurança dos trabalhadores da usina de triagem do município de Cianorte/PR. Os procedimentos utilizados foram a pesquisa bibliográfica, documental, entrevistas semiestruturadas com a utilização de questionários, observações in loco e registros fotográficos. Em seguida, foi realizada uma verificação dos tipos de riscos ocupacionais fundamentados nas exigências das Normas Regulamentadoras aplicáveis à usina de triagem para conhecer a situação dos trabalhadores da usina. Após a avaliação constatou-se que os trabalhadores estão expostos a riscos físicos, químicos, biológicos, ergonômicos e mecânicos. Dessa maneira, se torna fundamental a implementação de programas de treinamentos bem como a capacitação dos trabalhadores relacionada à saúde e segurança do trabalho.

PALAVRAS-CHAVE: Saúde e segurança dos trabalhadores. Usina de triagem. Riscos ocupacionais.

\section{INTRODUÇÃO}

\subsection{USINA DE TRIAGEM E CATADORES DE MATERIAIS RECICLÁVEIS}

Nos dias atuais, as usinas de triagem vêm sendo amplamente implantadas no Brasil em conjunto com cooperativas e associações de catadores como estratégia para aumentar a quantidade de materiais que podem ser submetidos ao processo de reciclagem. Estas usinas constituem um importante elemento para tratamento dos resíduos sólidos e para diminuir a quantidade de resíduos sólidos encaminhados a aterros sanitários. Porém, como em qualquer outra atividade laboral, nesses locais os trabalhadores estão expostos a diversos riscos ocupacionais (físicos, químicos, biológicos, ergonômicos e mecânicos) que podem comprometer a sua saúde e segurança (SOUSA, 2014). Assim, para proteger a integridade física dos colaboradores, o Ministério do Trabalho e Emprego criou, em 1978, as Normas Regulamentadoras (NR's) para orientar medidas a serem adotadas pelos empreendimentos em prol do trabalhador.

Os catadores que trabalham em usinas de triagem de resíduos são divididos em diferentes funções, pois nestes locais, não é somente realizada a separação dos recicláveis, mas também a prensagem, o enfardamento e o empilhamento destes fardos no galpão. Da mesma forma que acontece com os catadores dos lixões, os colaboradores de unidades de triagem convivem com o mau cheiro que exala dos recicláveis e com o manuseio dos resíduos orgânicos, visto que em muitas cidades os resíduos chegam misturados. Desta maneira, estes trabalhadores também correm o risco de se acidentarem e de se contaminarem, podendo contrair diversas doenças, assim como nos lixões, o que é agravado pelo fato destes, por diversas vezes, não utilizarem equipamentos de proteção individual (BARBOSA, 2011).

\subsection{RISCOS OCUPACIONAIS}

Riscos físicos: o odor, ruídos, a poeira, a vibração dos equipamentos, os objetos perfurantes e cortantes, e a questão estética, são agentes físicos que acometem os colaboradores (CARDOSO, 2012).

Riscos químicos: são considerados agentes químicos as substâncias, compostos ou produtos que possam penetrar no organismo por via respiratória, nas formas de poeiras, fumos, 


\section{Revista Latino-americana de Ambiente Construído \& Sustentabilidade ISSN 2675-7524 / v. 1, n. 2 (2020)}

névoas, neblinas, gases ou vapores, ou que possam ter contato ou serem absorvidos pelo organismo através da pele ou por ingestão (MOREIRA, 2017).

Riscos biológicos: Os agentes biológicos presentes nos resíduos sólidos podem ser responsáveis pela transmissão direta e indireta de doenças. Os microrganismos patogênicos ocorrem nos resíduos mediante a presença de lenços de papel, curativos, fraldas descartáveis, papel higiênico, absorventes, preservativos e até mesmo agulhas e seringas descartáveis originados da população (RENNÓ, 2010, CARDOSO, 2012).

Riscos ergonômicos: os riscos ergonômicos são aqueles que podem afetar os sistemas muscular e esquelético devido a movimentos corporais e esforços relacionados ao trabalho (RENNÓ, 2010).

Riscos mecânicos: Os riscos mecânicos ou de acidentes são aqueles que dizem respeito ao arranjo físico no local de trabalho, à ordem, a limpeza, aos sistemas de proteção dos maquinários, às sinalizações e outros cuidados importantes para garantir a segurança no trabalho (MOREIRA, 2017).

\subsection{NORMAS REGULAMENTADORAS APLICÁVEIS A USINA DE TRIAGEM}

O ministério do trabalho aprovou na Portaria no 3214/1978 (BRASIL, 1978) as normas regulamentadoras (NR's) relacionadas à Segurança e Medicina no Trabalho. No caso da usina de triagem, as normas que podem ser aplicadas para a proteção dos trabalhadores são:

NR 6 - Equipamentos de Proteção Individual (EPI): normatiza as questões relacionadas com a utilização dos EPI's definidos como dispositivo ou produto, utilizado pelo trabalhador, destinado à proteção de riscos capazes de ameaçar a integridade física e a saúde do trabalhador (BRASIL, 2017).

NR 10 - Segurança em Instalações e Serviços em Eletricidade: Estabelece os requisitos e as condições mínimas com o objetivo de uma implementação de medidas de controle e sistemas preventivos, garantindo a segurança e a saúde dos trabalhadores que, direta ou indiretamente, interajam em instalações elétricas e serviços com eletricidade (BRASIL, 2016).

NR 11 - Transporte, Movimentação, Armazenagem e Manuseio de Materiais: estipula normas de segurança para operação de elevadores, guindastes, transportadores industriais e máquinas transportadoras, nos quais os equipamentos utilizados na movimentação de materiais serão calculados e construídos de maneira que ofereçam as necessárias garantias de resistência e segurança, e sejam conservados em perfeitas condições (BRASIL, 2016).

NR 12 - Máquinas e Equipamentos: a norma estabelece parâmetros a serem seguidos nas instalações e área de trabalho, tais como, vistoria e limpeza dos pisos onde estão instaladas máquinas e equipamentos sempre que apresentarem riscos de acidentes devido à presença de substâncias que os tornem escorregadios (exemplo: graxas e óleos) (BRASIL, 2018).

NR 15 - Atividades e Operações Insalubres: considera-se atividades ou operações insalubres aquelas que se desenvolvem acima de limites de tolerância previstos para ruído contínuo ou intermitente, ruído de impacto, exposição ao calor, radiações ionizantes e não ionizantes, vibrações, frio, umidade, agentes químicos, poeiras minerais, entre outros agentes e esta norma visa diminuir os riscos de acidentes ocupacionais com foco na proteção dos trabalhadores contra estes efeitos (BRASIL, 2014). 
NR 17 - Ergonomia: visa estabelecer parâmetros que permitam a adaptação das condições de trabalho às características psicofisiológicas dos trabalhadores, de modo a proporcionar o máximo de conforto, segurança e desempenho eficiente. Para avaliar essa adaptação cabe ao empregador realizar a análise ergonômica do trabalho (BRASIL, 2007).

NR 23 - Proteção contra Incêndios: determina que todas as empresas devem possuir medidas de proteção contra incêndio, entre elas, dispor de saídas, em número suficiente e dispostas de modo que aqueles que se encontrem no local e em serviço possam sair com rapidez e segurança, em caso de incêndio (BRASIL, 2011).

NR 24 - Condições Sanitárias e de Conforto nos Locais de Trabalho: a norma aborda questões relacionadas às condições de higiene e conforto de instalações sanitárias, vestiários, alojamentos, refeitórios e cozinhas (BRASIL, 1993).

\section{OBJETIVOS}

Identificar os aspectos de saúde e segurança dos trabalhadores da usina de triagem do município de Cianorte/PR, bem como fundamentar nas exigências das Normas Regulamentadoras do Ministério do Trabalho e Emprego e apresentar medidas de controle e/ou prevenção de possíveis acidentes de trabalho visando a saúde e segurança do colaborador.

\section{METODOLOGIA}

Inicialmente, foi realizada uma revisão bibliográfica sobre a saúde e segurança dos trabalhadores nas etapas de separação de material reciclável e a caracterização do município de Cianorte/PR. Em seguida, foi solicitado a Secretaria Municipal de Meio Ambiente do município o consentimento para a realização das entrevistas desta pesquisa.

Para analisar a saúde e segurança dos trabalhadores da usina de triagem do município utilizou-se o questionário proposto por Sousa (2014) seguido de algumas alterações. As modificações realizadas no questionário foram: acréscimo de alternativas e de questão.

O questionário foi aplicado pessoalmente na usina de triagem e também foram realizadas visitas para identificação de riscos incidentes no ambiente de trabalho e para o conhecimento do processo de trabalho dos colaboradores. Dessa maneira, conseguiu-se obter o perfil dos trabalhadores, avaliar a saúde e a segurança dos mesmos, realizar a caracterização da usina de triagem e os possíveis riscos ambientais que os colaboradores estão sujeitos.

A coleta de dados teve como base a observação in loco referente a itens que foram fundamentados nos tipos de riscos ocupacionais (físicos, químicos, biológicos, ergonômicos e mecânicos) e nas exigências das Normas Regulamentadoras do Ministério do Trabalho e Emprego aplicáveis às etapas de separação do material reciclável.

\section{RESULTADOS}

\subsection{CARACTERIZAÇÃO DO MUNICÍPIO DE CIANORTE/PR}




\section{Revista Latino-americana de Ambiente Construído \& Sustentabilidade ISSN 2675-7524 / v. 1, n. 2 (2020)}

Cianorte foi fundada pela Companhia Melhoramentos Norte do Paraná, da qual herdou o nome: Cia (Companhia) e norte (de Norte do Paraná), em 26 de Julho de 1953. O município de Cianorte localiza-se na Mesorregião Noroeste do estado do Paraná e conta com dois distritos, São Lourenço e Vidigal, em uma área territorial de 811,666 km2 (PMC, 2018). Sua população total estimada para 2019 é de 82.620 habitantes (IBGE, 2019). De acordo com a classificação de Köppen, o município de Cianorte possui o clima Cfa: subtropical; temperatura média no mês mais frio inferior a $18^{\circ} \mathrm{C}$ (mesotérmico) e temperatura média no mês mais quente acima de $220 \mathrm{C}$, com verões quentes, geadas pouco frequentes e tendência de concentração das chuvas nos meses de verão, contudo sem estação seca definida (IAPAR, s.d.).

\subsection{ASPECTOS DE SAÚDE E SEGURANÇA DOS TRABALHADORES DA USINA DE TRIAGEM DE CIANORTE/PR}

\subsubsection{Perfil dos Trabalhadores da Usina de Triagem}

A usina de triagem chamada de Associação Assistencial dos Agentes Ambientais de Reciclagem de Cianorte atualmente possui treze associados, sendo sete homens e seis mulheres, porém a quantidade de trabalhadores altera com frequência. Destes, três são naturais de Cianorte/PR, sete nasceram em outros municípios paranaenses, três nasceram em outros Estados brasileiros como Ceará, Mato Grosso e Pernambuco.

A faixa etária dos mesmos situa-se entre 23 a 65 anos, sendo expressiva a variação de idade. Com relação ao grau de escolaridade nove possuem ensino fundamental incompleto, dois possuem ensino fundamental completo e dois, o ensino médio incompleto.

Seis dos associados tem familiares que trabalham no mesmo local. Dentre os trabalhadores, cinco recebem benefício social que complementam a renda familiar: quatro são beneficiados com bolsa família e um é aposentado. A usina não recolhe a contribuição previdenciária (INSS), portanto todos os associados trabalham como autônomos.

Antes de trabalhar na usina onze associados exerceram atividades diversas, por exemplo, auxiliar de produção em avícola, agricultura (aplicador de agrotóxico, colheita, carpinagem), empregada doméstica, costureira, cozinheira, pedreiro, operador de máquina em lavanderia, motorista, tratorista, e dois já trabalharam com separação de recicláveis em empresas privadas. Há pessoas que estão nessa atividade há 6 anos e alguns trabalharam muitos anos na associação, saíram para atuar em outro serviço e acabaram voltando para a usina de triagem.

A jornada diária de trabalho nesse local é de 8 horas com pausas de uma 1 hora e 30 minutos para o almoço e 30 minutos para o café da tarde. Onze estão satisfeitos com o trabalho que exercem e dois não estão satisfeitos com o seu trabalho, pois um queria trabalhar em outra área e o outro gostaria de ficar apenas na separação, não exercendo outras atividades na usina de triagem, como por exemplo a limpeza do local, que deveria haver uma pessoa contratada apenas para realizar essa tarefa. Quando questionados sobre as melhorias que poderiam ser feitas no ambiente de trabalho cinco responderam que não há necessidade de melhorias, quatro gostariam de melhor infraestrutura do local como concretar o pátio, quatro gostariam do aumento de um barracão para armazenagem dos materiais e que a população tivesse mais 


\section{Revista Latino-americana de Ambiente Construído \& Sustentabilidade ISSN 2675-7524 / v. 1, n. 2 (2020)}

conscientização na hora de separar o resíduo em casa, pois ainda chega muito material orgânico na usina de triagem.

\subsubsection{Saúde e Segurança na Usina de Triagem}

No que diz respeito aos hábitos de fumar e de ingerir bebida alcoólica, sete dos associados são fumantes, seis ingerem bebida alcóolica aos finais de semana e quatro não apresentam nenhum destes vícios/costumes.

As queixas de dores apresentadas foram: câimbras, cansaço, dores nos pés, nas mãos, na coluna, nas costas, no pescoço, nos ombros, nos joelhos, dores de cabeça, doenças respiratórias (asma, bronquite), insônia e um trabalhador não apresentou nenhuma queixa. As queixas mais frequentes foram sentir cansaço, dores na coluna e nas costas.

Quanto aos exames médicos, seis dos entrevistados disseram fazer regularmente, ao menos uma vez ao ano enquanto e sete alegaram raramente realizar algum tipo de exame. Já quanto às vacinas, nove estão com a carteira de vacinação em dia, dois tomaram a vacina antitetânica, um não se tomou alguma vacina e um nunca tomou nenhuma dessas vacinas. A Secretaria de Saúde do município compareceu na usina para aplicar as vacinas nos trabalhadores e outros foram no posto de saúde para tomar a vacina.

A usina de triagem possui um equipamento de elevação de cargas, sendo esta a empilhadeira para que seja possível o levantamento de fardos e bags para armazenamento no barracão ou para transporte em caminhões, porém para realizar a separação dos materiais, os trabalhadores costumam carregar bags com aproximadamente 150 quilos, variando de material para material, a uma distância aproximada de 5 metros.

Com relação à ocorrência de acidentes de trabalho, a maioria dos entrevistados não considerava cortes nas mãos, pés, pernas, em outros locais do corpo ou ferimentos com objetos perfurocortantes como acidentes de trabalho. Dos trabalhadores quatro nunca sofreram nenhum tipo de acidente, três tiveram cortes nas mãos, dois cortes nos pés, um corte nas pernas, oito tiveram ferimentos com objetos perfurocortantes, como vidros armazenados de maneira incorreta ou seringas, um caiu algo nas mãos, um no pés e dois nas pernas, como por exemplo bags com materiais recicláveis.

Sobre os trabalhadores considerarem algo no ambiente de trabalho que seja prejudicial à saúde, três consideram os vetores de doenças, pois existe um grande número de ratos, baratas e pernilongos no local. Os outros acreditam que não existe nada de prejudicial à saúde no ambiente de trabalho.

A usina de triagem de Cianorte teve início das suas atividades em 2007 e desde então houve alguns treinamentos ou informações sobre a prevenção de acidente no desempenho da atividade. Em 2017, o Serviço Social da Indústria (SESI) do município realizou uma palestra para informar os trabalhadores da usina sobre prevenção de acidente e a importância da utilização de equipamentos de proteção individual (EPI's). Vale ressaltar, que alguns membros da associação entraram há pouco tempo, assim, nem todos receberam este treinamento, porém sempre que entra um novo associado, o presidente da associação repassa as instruções recebidas.

Todos os trabalhadores da usina têm acesso aos seguintes EPI's durante sua jornada 
de trabalho: luva, máscara de proteção (utilizado pelos trabalhadores apenas ao manusear resíduos com cheiro desagradável) e os colaboradores que manuseiam a prensa têm acesso ao protetor auricular, mas nem todos utilizam estes equipamentos. Durante visita, observou-se que os trabalhadores utilizam sapato fechado mas não utilizam uniforme, porém estão com projetos para realização de uniformes. Notou-se também que não há obrigação e nem fiscalização na utilização dos EPI's.

Não houve treinamento de combate a incêndio, mas em visita ao local, constatou-se que há vários extintores para situações de emergência, sendo que em cada barracão há dois extintores. E quando foi perguntado sobre o que poderia ser feito para melhorar a segurança, quatro associados responderam que gostariam de um uniforme com um material que ajudasse a proteger dos riscos ocupacionais e trouxesse mais segurança e um gostaria que houvesse disponibilização de álcool em gel para evitar possíveis doenças.

\subsubsection{Caracterização da Usina de Triagem}

A usina de triagem é composta por uma estrutura física para receber os materiais recicláveis e realizar sua separação, prensagem, enfardamento, armazenamento e venda. Essa estrutura compreende dois galpões e unidades de apoio com escritório, cozinha/refeitório e sanitários, um destinado ao sexo masculino e outro ao feminino. Os barracões juntamente com as unidades de apoio correspondem a 4.456,85 $\mathrm{m}^{2}$ (contendo um galpão com 491,89 $\mathrm{m}^{2}$ e outro com $\left.300 \mathrm{~m}^{2}\right)$. Os galpões são de pisos concretados cobertos com telhas de fibrocimento, porém a parte externa é de pedregulho.

As máquinas e os equipamentos existentes no local são: duas mesas de triagem, três prensas hidráulicas de pequeno porte, uma empilhadeira, um elevador, uma esteira e uma balança. A rotina operacional da usina de triagem inicia-se com a recepção dos materiais recicláveis onde a descarga ocorre diretamente nas mesas de triagem ou na área externa. Se as mesas de triagem estão lotadas, o caminhão da coleta seletiva descarrega os resíduos na área externa. Quando as sacolas são leves, os associados as levam para a mesa de triagem, mas quando as sacolas estão pesadas são encaminhadas com a empilhadeira próximo as mesas de triagem para posterior separação. Devido a usina obter apenas uma empilhadeira, alguns trabalhadores levam as bags até a mesa de triagem por conta própria.

Após esta etapa é realizada a triagem, ou seja, a separação manual da matéria orgânica e dos materiais recicláveis de acordo com sua natureza (papel, papelão, PET, plástico, metais e vidro) para posterior comercialização (PET branco, PET verde, PET terceiro, plástico branco, plástico colorido, papel branco, papel colorido, PP plástico duro, PP plástico maleável, garrafinha, alumínio pesado, alumínio leve, ferro e vidro).

A coleta seletiva de resíduos do município ultimamente não está sendo satisfatória, pois houve um aumento da mistura de resíduos recicláveis com orgânicos, tecidos, deixando o processo de triagem mais demorado, bem como o número de atravessadores aumentaram, diminuindo então a quantidade de materiais recicláveis que chegariam até a usina de triagem.

Para facilitar a separação, há a retirada na área de recepção dos resíduos maiores, como sucatas de eletrodomésticos, utensílios plásticos, metais, entre outros e os menores são encaminhados às mesas de triagem. Uma mesa de triagem é metade de concreto e metade de 


\section{Revista Latino-americana de Ambiente Construído \& Sustentabilidade ISSN 2675-7524 / v. 1, n. 2 (2020)}

madeira e a outra mesa de triagem é de madeira, possuindo uma altura adequada (aproximadamente de $90 \mathrm{~cm}$ ) para a operação dos trabalhadores porém com tamanhos inapropriados, dificultando a separação.

Quando houve a concessão do segundo barracão, a prefeitura contribuiu com alguns equipamentos, como a esteira, para facilitar na separação de materiais, porém em pouco tempo o material da esteira se desgastou e não está sendo mais utilizada. Seria de extrema importância o uso da esteira, pois esta é fundamental para agilizar o processo de separação de materiais, aumentando a produtividade.

Após a separação, os materiais triados são armazenados em bags de plásticos localizadas atrás dos empregados dispostos à mesa de triagem. Quando essas bags estão cheias, os materiais são levados para serem prensados, em seguida são enfardados e depositados no barracão ou na área externa.

Não há baias de recicláveis, com uma área exclusiva para depósito dos fardos até a comercialização. Deste modo, constatou-se que o arranjo físico da usina não é adequado e se encontra desorganizado, uma vez que, os galpões ficam sobrecarregados pelo acúmulo de materiais recicláveis e as pilhas de fardos formadas são dispostas de forma desorganizada no local, dificultando a passagem e a circulação dos trabalhadores podendo causar acidentes e ferimentos e em alguns casos, ficando expostas a céu aberto, acumulando água em dias chuvosos, acarretando assim em possíveis focos de vetores de doenças.

Os materiais recicláveis enfardados são mantidos no barracão por um período médio de 15 dias até a venda, porém esse período pode variar dependendo da quantidade de materiais que chegam na usina e a separação dos mesmos. Os resíduos orgânicos e os tecidos são embalados em sacos e o caminhão de coleta convencional da SANEPAR recolhe esses resíduos toda quarta-feira e quinta-feira da semana.

\subsection{IDENTIFICAÇÃO DE RISCOS OCUPACIONAIS POR SETOR DA USINA DE TRIAGEM}

\subsubsection{Escritório}

O escritório é o local de trabalho de apenas uma funcionária que realiza suas atividades tanto na posição sentada como também na realização das operações bancárias, ação social entre outros, não permanecendo o dia inteiro no escritório. Dessa maneira, os danos em relação à sua saúde são mínimos, devido à movimentação no seu dia a dia. Porém, em certos dias a permanência no escritório é maior e acaba não tomando os devidos cuidados com relação à sua postura, queixando-se assim de dores na coluna.

Conforme a norma regulamentadora NR 17 que trata sobre Ergonomia, para evitar ou minimizar possíveis desconfortos pode ser adotada a ginástica laboral no decorrer da sua jornada de trabalho e em relação a cadeira ergonômica ajustável à estatura do trabalhador e à natureza da tarefa está de acordo com a norma. O Quadro 1 traz um resumo do risco e do agente de risco no escritório, além de apresentar as medidas de controle e/ou prevenção para o ambiente de trabalho. 
Quadro 1: Análise do setor (escritório) da usina de triagem de Cianorte/PR

\begin{tabular}{|c|c|c|c|c|}
\hline $\begin{array}{c}\text { Setor do } \\
\text { empreendimento }\end{array}$ & Risco & Agente & NR aplicável & $\begin{array}{c}\text { Medidas de } \\
\text { controle/prevenção }\end{array}$ \\
\hline Escritório & Ergonômico & $\begin{array}{c}\text { Postura } \\
\text { inadequada }\end{array}$ & NR 17 & Ginástica laboral \\
\hline
\end{tabular}

Fonte: AUTORA (2020)

\subsubsection{Instalações sanitárias}

As instalações sanitárias da usina de triagem são separadas de acordo com o sexo dos trabalhadores (masculino e feminino). A norma regulamentadora 24 trata sobre Condições Sanitárias e de Conforto nos Locais de Trabalho e estabelece que para cada grupo de 20 trabalhadores, deve ser adotada, no mínimo, uma instalação sanitária, constituída por vaso sanitário, mictório, lavatório e chuveiro. A usina atende a esta norma.

Nos banheiros, os trabalhadores estão sujeitos a risco biológico devido à presença de microrganismos patogênicos (bactérias, parasitas, fungos, protozoários, etc) que podem causar doenças. Dessa forma, torna-se necessário que haja higienização do local diariamente, que todos os empregados sejam vacinados e façam exames médicos regularmente. No Quadro 2 é possível visualizar o risco a que os trabalhadores estão expostos e quais as medidas de controle/prevenção que devem ser adotadas.

Quadro 2: Análise do setor (sanitários) da usina de triagem de Cianorte/PR

\begin{tabular}{|c|c|c|c|c|}
\hline $\begin{array}{c}\text { Setor do } \\
\text { empreendimento }\end{array}$ & Risco & Agente & NR aplicável & $\begin{array}{c}\text { Medidas de } \\
\text { controle/prevenção }\end{array}$ \\
\hline Sanitários & Biológico & $\begin{array}{c}\text { Microrganismos } \\
\text { patogênicos }\end{array}$ & NR 24 & $\begin{array}{c}\text { Higienização do local } \\
\text { diariamente; } \\
\text { Vacinação; } \\
\text { Exames médicos } \\
\text { regularmente. }\end{array}$ \\
\hline
\end{tabular}

Fonte: AUTORA (2020)

\subsubsection{Cozinha/Refeitório}

A NR 24 (Condições Sanitárias e de Conforto nos Locais de Trabalho) estabelece que os locais de refeições para atender até 30 trabalhadores devem possuir assentos e mesas, balcões ou similares suficientes para todos os usuários atendidos e o refeitório da usina não atende a estes critérios. Porém, os requisitos de limpeza e arejamento asseguram as condições de conforto para a ocasião das refeições.

\subsubsection{Recepção de resíduos}

Neste setor, o caminhão da coleta seletiva chega na usina e descarrega as sacolas com resíduos nas mesas de triagem (que estão dentro dos barracões) ou quando estas estão cheias na área externa da usina (que não possui cobertura). Quando o despejo ocorre na área externa os trabalhadores que são encarregados de encaminhar os resíduos sólidos nas mesas de triagem para posterior separação. Quando são sacolas leves, os associados levam até as mesas de triagem, mas quando são sacolas pesadas há dois trabalhadores do sexo masculino responsáveis 


\section{Revista Latino-americana de Ambiente Construído \& Sustentabilidade ISSN 2675-7524 / v. 1, n. 2 (2020)}

em levar as sacolas até as mesas com a empilhadeira, evitando que tenham um esforço físico intenso. Os riscos analisados foram quando os resíduos são descarregados na área externa da usina expondo assim os trabalhadores ao sol e as intempéries bem como o risco ergonômico (NR 17) devido ao carregamento excessivo de sacolas (mesmo que estas sejam leves) e a postura inadequada para tal atividade.

Na recepção de resíduos, eles também estão expostos a riscos biológicos devido ao contato direto com as sacolas de resíduos que podem estar contaminadas com microrganismos patogênicos bem como a riscos de acidentes, como cortes e perfurações com resíduos mal embalados e devido ao mau uso de EPI's. Notou-se também que os cooperados estão expostos a poeiras e ao ruído do caminhão de coleta seletiva.

Dessa maneira, os trabalhadores estão expostos aos riscos físicos, biológicos, químicos e de acidentes. Neste caso, conforme a NR 6 que se refere à Equipamentos de Proteção Individual, os riscos podem ser prevenidos por meio da utilização de EPI's adequados. Assim, tal situação e recomendações são apresentadas no Quadro 3.

Quadro 3: Análise do setor (recepção de resíduos) da usina de triagem de Cianorte/PR

\begin{tabular}{|c|c|c|c|c|}
\hline $\begin{array}{c}\text { Setor do } \\
\text { empreendimento }\end{array}$ & Risco & Agente & NR aplicável & $\begin{array}{c}\text { Medidas de } \\
\text { controle/prevenção }\end{array}$ \\
\hline \multirow{7}{*}{ Recepção de resíduos } & Ergonômico & $\begin{array}{c}\text { Ruído } \\
\text { Exposição ao sol e } \\
\text { intempéries }\end{array}$ & $\begin{array}{c}\text { NR 6 } \\
\text { NR } 15\end{array}$ & Utilização de EPI's \\
\cline { 2 - 5 } & $\begin{array}{c}\text { Carregamento } \\
\text { Postura } \\
\text { inadequada }\end{array}$ & NR 17 & $\begin{array}{c}\text { Períodos de descanso; } \\
\text { Ginástica laboral }\end{array}$ \\
\cline { 2 - 5 } & Biológico & $\begin{array}{c}\text { Microrganismos } \\
\text { patogênicos }\end{array}$ & NR 6 & $\begin{array}{c}\text { Vacinação; } \\
\text { Utilização de EPI's. }\end{array}$ \\
\cline { 2 - 5 } & Químico & Poeira & NR 6 & Utilização de EPI's \\
\cline { 2 - 5 } & Acidentes & $\begin{array}{c}\text { Cortes } \\
\text { Perfurações }\end{array}$ & NR 6 & Utilização de EPI's \\
\hline
\end{tabular}

Fonte: AUTORA (2020)

\subsubsection{Separação de materiais recicláveis}

Esta etapa possui o maior número de trabalhadores para operação sendo um dos setores do empreendimento de grande relevância na identificação dos riscos ambientais existentes no local e suas medidas de prevenção. Os cooperados encarregados da separação dos recicláveis realizam suas atividades em pé, na maioria das vezes ficam com uma postura inadequada em relação a inclinação do tronco e torções da região lombar, praticam movimentos repetitivos e acabam possuindo um ritmo excessivo de trabalho. De acordo com a norma regulamentadora 17 (Ergonomia) todas as atividades em que as tarefas devem ser realizadas em pé, recomenda-se colocar assentos para descanso em locais que possam ser utilizados por todos os trabalhadores durante os intervalos. Porém, na associação não há cadeiras disponíveis em quantidade suficiente.

Na realização da triagem que há o contato direto do trabalhador com os resíduos, existe a exposição dos associados a agentes patogênicos. Estes podem transmitir doenças caso não sejam adotadas medidas corretas de proteção, tais como vestimentas de trabalho, aventais, 
luvas, máscaras ou escudos faciais e higienização do local, como consta na NR 6 (Equipamentos de Proteção Individual - EPI).

No momento da separação pode haver misturado aos materiais recicláveis os resíduos orgânicos e os resíduos perigosos (lâmpadas fluorescentes, pilhas, baterias, tintas, produtos químicos, etc). Em relação aos orgânicos, temos um agente de risco químico que são os gases que estes liberam devido a sua decomposição e os resíduos perigosos contêm substâncias químicas que em contato com o ser humano ou o meio ambiente apresentam características de bioacumulação e riscos de contaminação devendo assim ser encaminhados a uma destinação correta.

Na triagem, os trabalhadores também estão expostos ao risco físico devido aos ruídos emitidos pela prensa hidráulica. Tanto no risco químico quanto no físico, aplicam-se a NR 15 (Atividades e Operações Insalubres) bem como a NR 6 (Equipamentos de Proteção Individual EPI).

O risco de acidentes também pode ocorrer durante as atividades de triagem, pois há com frequência materiais perfurocortantes como cacos de vidro, agulhas, seringas, entre outros misturados nos resíduos domiciliares, necessitando dessa maneira de Equipamentos de Proteção Individual - NR 6. Dessa maneira, observa-se a falta de conscientização dos munícipes no momento do descarte e acondicionamento correto dos resíduos e a necessidade do emprego de uma educação ambiental efetiva. A partir da análise do setor de triagem do empreendimento apresenta-se o Quadro 4.

Quadro 4: Análise do setor (triagem de resíduos) da usina de triagem de Cianorte/PR

\begin{tabular}{|c|c|c|c|c|}
\hline $\begin{array}{c}\text { Setor do } \\
\text { empreendimento }\end{array}$ & Risco & Agente & NR aplicável & $\begin{array}{c}\text { Medidas de } \\
\text { controle/prevenção }\end{array}$ \\
\hline \multirow{5}{*}{ Triagem de resíduos } & Ergonômico & $\begin{array}{l}\text { Postura } \\
\text { inadequada } \\
\text { Movimentos } \\
\text { repetitivos } \\
\text { Ritmo } \\
\text { excessivo }\end{array}$ & NR 17 & $\begin{array}{c}\text { Ginástica laboral; } \\
\text { Assentos disponíveis em } \\
\text { quantidade. }\end{array}$ \\
\hline & Biológico & $\begin{array}{l}\text { Microrganis- } \\
\text { mos } \\
\text { patogênicos }\end{array}$ & NR 6 & $\begin{array}{l}\text { Vacinação; } \\
\text { Higienização do local } \\
\text { regularmente; } \\
\text { Dedetização do local; } \\
\text { Utilização de EPI's; }\end{array}$ \\
\hline & Químico & $\begin{array}{l}\text { Produtos } \\
\text { químicos } \\
\text { Gases }\end{array}$ & $\begin{array}{l}\text { NR } 6 \\
\text { NR } 15\end{array}$ & Utilização de EPI's; \\
\hline & Físico & Ruído & $\begin{array}{l}\text { NR } 6 \\
\text { NR15 }\end{array}$ & Utilização de EPI's \\
\hline & Acidentes & $\begin{array}{c}\text { Cortes } \\
\text { Perfurações }\end{array}$ & NR 6 & Utilização de EPI's; \\
\hline
\end{tabular}

Fonte: AUTORA (2020)

\subsubsection{Prensagem de materiais recicláveis}

Após a triagem de recicláveis, ocorre a prensagem dos materiais que é realizada por dois trabalhadores do sexo masculino que utilizam uma prensa hidráulica razoavelmente conservada. Porém, a utilização do equipamento deve ser de forma cuidadosa, pois em caso de 


\section{Revista Latino-americana de \\ Ambiente Construído \& Sustentabilidade \\ ISSN 2675-7524 / v. 1, n. 2 (2020)}

defeito ou descuido na operação da prensa pode haver riscos de esmagamento de membros, principalmente os superiores. Dessa maneira, a NR 12 que trata sobre Máquinas e Equipamentos estabelece condições de segurança para os trabalhadores como equipar as máquinas e equipamentos com botões de parada rápida e dispor de proteção nas partes móveis, cortantes ou não, como correias, motores, serras, prensas etc.

A posição da prensa hidráulica no local deve ser adequada e impõe-se tomar todas as medidas de controle e prevenção para evitar choques elétricos a partir das recomendações da Norma Regulamentadora 10 que dispõe sobre Segurança em Instalações e Serviços em Eletricidade. Outra ação fundamental é realizar o treinamento do operador do equipamento e adotar os EPI's (NR 6) contra ruído e vibração decorrentes da prensa.

Os associados encarregados de levar os materiais separados até a prensa utilizam a empilhadeira para carregar os bags com materiais pesados e os materiais considerados leves são carregados a mão, não realizando trabalho físico pesado. Porém, devido ao contato direto com estes bags com resíduos, os trabalhadores estão expostos a riscos biológicos e químicos. Tais situações descritas são apresentadas no Quadro 5.

Quadro 5: Análise do setor (prensagem de materiais recicláveis) da usina de triagem de Cianorte/PR

\begin{tabular}{|c|c|c|c|c|}
\hline $\begin{array}{c}\text { Setor do } \\
\text { empreendimento }\end{array}$ & Risco & Agente & NR aplicável & $\begin{array}{c}\text { Medidas de } \\
\text { controle/prevenção }\end{array}$ \\
\hline \multirow{2}{*}{$\begin{array}{c}\text { Prensagem de } \\
\text { materiais recicláveis }\end{array}$} & Acidentes & $\begin{array}{c}\text { Esmagamento de } \\
\text { membros } \\
\text { Choque elétrico }\end{array}$ & $\begin{array}{c}\text { Treinamento do } \\
\text { operador; } \\
\text { Posicionamento } \\
\text { NR } 10 \\
\text { adequado da prensa no } \\
\text { local; }\end{array}$ \\
\cline { 2 - 5 } & Físico & $\begin{array}{c}\text { Ruído } \\
\text { Vibração }\end{array}$ & $\begin{array}{c}\text { Isolamento do sistema } \\
\text { elétrico da prensa; } \\
\text { Aterramento elétrico. }\end{array}$ \\
\cline { 2 - 5 } & Biológico & $\begin{array}{c}\text { Microrganismos } \\
\text { patogênicos }\end{array}$ & NR 6 15 & Utilização de EPI's \\
\cline { 2 - 5 } & Químico & Produtos químicos & $\begin{array}{c}\text { NR } 6 \\
\text { NR 15 }\end{array}$ & Utilização de EPI's \\
\cline { 2 - 5 } & & Utilização de EPI's \\
\hline
\end{tabular}

Fonte: AUTORA (2020)

\subsubsection{Armazenamento e transporte de materiais recicláveis}

Neste setor, a usina não disponibiliza baias para o armazenamento adequado dos resíduos enfardados para posterior comercialização. Dessa maneira, há o acúmulo de fardos dispostos de forma desorganizada tanto dentro dos barracões como na área externa, sobrecarregando o local e dificultando a circulação dos trabalhadores. Portanto, fica evidente que o arranjo físico é inadequado, favorecendo o risco de acidentes. Deve-se considerar a possibilidade de risco biológico, pois as pilhas de materiais recicláveis podem inocular microrganismos patogênicos.

Além disso, no ambiente há riscos de incêndios, mas em cada barracão há dois extintores instalados caso ocorra algum incêndio, distribuídos adequadamente no local. Porém, o local deveria ter o um projeto de prevenção de incêndio, que visa treinar pessoas para prevenir 


\section{Revista Latino-americana de}

Ambiente Construído \& Sustentabilidade

ISSN 2675-7524 / v. 1, n. 2 (2020)

e combater princípios de incêndios, visando garantir a segurança do local e a preservação de vidas. A realização treinamentos de combate a incêndios se torna fundamental, de acordo com as recomendações da NR 23 que dispõe sobre Proteção Contra Incêndios.

Neste setor, não há risco ergonômico, pois os trabalhadores utilizam a empilhadeira tanto para o armazenamento quanto para o transporte de fardos.

A NR 11 que trata sobre Transporte, Movimentação, Armazenagem e Manuseio de Materiais, relata normas de segurança em atividades de transporte e levantamento manual de sacos, bem como, operações de carga e descarga. A norma descreve proposições para o armazenamento de materiais, entre elas, que o material deve ser disposto de forma a evitar a obstrução de portas, equipamentos contra incêndio, saída de emergências, etc.

No local encontra-se ainda, a prensa hidráulica, portanto, pode haver intensos níveis de ruído no ambiente. O Quadro 6 apresenta estes e outros riscos presentes nas áreas de armazenamento de recicláveis e no seu transporte.

Quadro 6: Análise do setor (armazenamento e transporte de materiais recicláveis) da usina de triagem de Cianorte/PR

\begin{tabular}{|c|c|c|c|c|}
\hline $\begin{array}{c}\text { Setor do } \\
\text { empreendimento }\end{array}$ & Risco & Agente & NR aplicável & $\begin{array}{c}\text { Medidas de } \\
\text { controle/prevenção }\end{array}$ \\
\hline \multirow{3}{*}{$\begin{array}{l}\text { Armazenamento e } \\
\text { transporte de } \\
\text { materiais recicláveis }\end{array}$} & Acidentes & $\begin{array}{l}\text { Arranjo físico } \\
\text { inadequado } \\
\text { Incêndio }\end{array}$ & $\begin{array}{l}\text { NR } 6 \\
\text { NR } 11 \\
\text { NR } 23\end{array}$ & $\begin{array}{c}\text { Utilização de EPI's; } \\
\text { Instalações elétricas } \\
\text { adequadas; } \\
\text { Treinamento de } \\
\text { combate a incêndio e } \\
\text { evacuação do local; } \\
\text { Elaboração do plano de } \\
\text { prevenção de incêndios. }\end{array}$ \\
\hline & Físico & Ruído & $\begin{array}{l}\text { NR } 6 \\
\text { NR } 15\end{array}$ & Utilização de EPI's \\
\hline & Biológico & $\begin{array}{l}\text { Microrganismos } \\
\text { patogênicos }\end{array}$ & NR 6 & $\begin{array}{c}\text { Vacinação; } \\
\text { Higienização do local } \\
\text { diariamente; } \\
\text { Dedetização do local; } \\
\text { Utilização de EPI's. }\end{array}$ \\
\hline
\end{tabular}

Fonte: AUTORA (2020)

\section{CONCLUSÃO}

A presente pesquisa teve como objetivo geral avaliar a condição de trabalho dos colaboradores da usina de triagem do município, através da aplicação de um questionário e observações in loco. A conclusão sobre as condições de trabalho dos colaboradores na usina de triagem do município de Cianorte/PR, avaliando a atual exposição dos trabalhadores. Através da análise dos riscos ocupacionais ficou evidente que devem ser implementados programas de treinamentos e de capacitação dos trabalhadores em relação à saúde e segurança do trabalho. Torna-se fundamental a realização desses programas a fim de prevenir/remediar a ocorrência de acidentes e de doenças do trabalho; apresentar a importância da utilização dos equipamentos de proteção individual, a maneira correta de utilizá-los e exigir a correta higiene e manutenção desses equipamentos. Observou-se que as condições de trabalho dos empregados da usina são insalubres, com exposição dos trabalhadores a riscos físicos, químicos, biológicos, ergonômicos e de acidentes. Assim, é importante seguir na busca de melhores 
processos produtivos bem como as condições de trabalho, não colocando em risco a integridade dos cooperados, nem causando prejuízos a sua saúde e segurança.

Diante do exposto, torna-se essencial maior atenção e apoio do poder público no que diz respeito aos resíduos sólidos urbanos bem como na saúde e segurança dos trabalhadores nas usinas de triagem, com investimentos no setor e adoção de medidas e programas para melhorar a qualidade do trabalho, proporcionar ganhos nos aspectos socioambientais e assim, evitar impactos negativos no meio ambiente.

\section{REFERÊNCIAS BIBLIOGRÁFICAS}

BARBOSA, M. Condições de trabalho em unidades de triagem de resíduo sólido de Campinas, SP: caracterização e percepção de catadores. Tese (Doutorado) - Pós-Graduação da Faculdade de Engenharia Civil, Arquitetura e Urbanismo. Campinas: Unicamp, 2011. 184 p.

BRASIL. Portaria no 3.214, de 08 de junho de 1978. Aprova as normas regulamentadoras - NR - do Capítulo V, Título II, da Consolidação das Leis do Trabalho relativas a Segurança e Medicina do Trabalho. Brasília, 1978.

. Ministério do Trabalho. NR 6 - Equipamento de Proteção Individual - EPI. Brasília, 2017.

. Ministério do Trabalho. NR 10 - Segurança em Instalações e Serviços em Eletricidade. Brasília, 2016.

Ministério do Trabalho. NR 11 - Transporte, Movimentação, Armazenagem e Manuseio de Materiais. Brasília, 2016.

. Ministério do Trabalho. NR 12 - Segurança no Trabalho em Máquinas e Equipamentos. Brasília, 2018.

Ministério do Trabalho. NR 15 - Atividades e Operações Insalubres. Brasília, 2014.

. Ministério do Trabalho. NR 17 - Ergonomia. Brasília, 2007.

. Ministério do Trabalho. NR 23 - Proteção Contra Incêndios. Brasília, 2011.

Ministério do Trabalho. NR 24 - Condições Sanitárias e de Conforto nos Locais de Trabalho. Brasília, 1993.

CARDOSO, R. K. Condições de saúde e trabalho de coletores de lixo. Dissertação (Mestrado) - Programa de Pós Graduação em Educação Física. Pelotas: Universidade Federal de Pelotas, Pelotas, 2012. 140 p.

COMPANHIA DE SANEAMENTO DO PARANÁ (SANEPAR). Resíduos Sólidos. [s.d.]. Disponível em: <http://site.sanepar.com.br/a-sanepar/servicos/residuos-solidos> Acesso em: 09 ago. 2019.

INSTITUTO AGRONÔMICO DO PARANÁ (IAPAR). Cartas Climáticas do Paraná. Londrina, [s.d.]. Disponível em: <http://www.iapar.br/modules/conteudo/conteudo.php?conteudo=597> Acesso em: 09 ago. 2019.

INSTITUTO BRASILEIRO DE GEOGRAFIA E ESTATístICA (IBGE). Panorama. Brasil, 2019. Disponível em: <https://cidades.ibge.gov.br/brasil/pr/cianorte/panorama> Acesso em: 10 fev. 2020.

MOREIRA, A. M. M. Riscos e agravos à saúde do trabalhador em centrais de triagem de materiais recicláveis. Tese (Doutorado) - Programa de Saúde Pública - Faculdade de Saúde Pública. São Paulo: USP, 2017. 219 p.

PREFEITURA MUNICIPAL DE CIANORTE (PMC). História da cidade. 2018. Disponível em: <http://www.cianorte.pr.gov.br/sobre/historia-da-cidade> Acesso em: 08 ago. 2019.

RENNÓ, V. M. Avaliação de riscos de acidentes ocupacionais na usina de triagem e compostagem de resíduos sólidos em Turvolândia-MG. Dissertação (Mestrado) - Curso de Mestrado Profissionalizante em Sistemas de Produção Agropecuária. Alfenas: Universidade José do Rosário Vellano, 2010. 75 p. 
Revista Latino-americana de Ambiente Construído \& Sustentabilidade ISSN 2675-7524 / v. 1, n. 2 (2020)

SOUSA, L. Avaliação do gerenciamento de resíduos sólidos urbanos no município de Jesuítas-PR. Dissertação (Mestrado) - Programa de Pós-Graduação em Engenharia Urbana. Maringá: UEM, 2014. 128 p. 